\title{
Artificial Neural Network for Classification and Analysis of Degraded Soils
}

\author{
A. Bonini Neto, C. S. B. Bonini, B. S. Bisi, L. F. S. Coletta AND A. R. dos Reis
}

\begin{abstract}
This study aimed to evaluate the Artificial Neural Network (ANN) to establish a classification and analysis of degraded soils and its recovery in response to lime and gypsum application. The analyzed degraded soil was classified as Oxisol, and the physical attributes considered were: soil density, soil porosity (macroporosity and microporosity) and soil penetration resistance. The ANN used in this study is the backpropagation composed of two layers, the middle layer and the output layer, with supervised training. The network has four inputs, that are the physical attributes of the soil, in the middle layer the network contains ten neurons and the output layer only one neuron, which has the function of informing if the soil was recovered $(R)$, partially recovered $(P R)$ or not recovered (NR). The analyzed data come from the year 2012, concerning the depths $0.0-0.1 \mathrm{~m}$, $0.1-0.2 \mathrm{~m}$ and $0.2-0.4 \mathrm{~m}$. Considering the performance of $\mathrm{ANN}$, it was verified that the network obtained an adequate training to classify the degraded soils, showing low mean square error of analyzed data. Therefore, ANN is considered an interesting alternative and a powerful automatic tool to classify degraded soils during recovery process.
\end{abstract}

Keywords - Soil physics, Artificial intelligence, Recovery of soil, Intelligent systems.

\section{INTRODUÇÃO}

A S REDES Neurais Artificiais (RNAs) são sistemas computacionais adaptativos inspirados no processamento de informação realizado por neurônios biológicos, tal como aqueles existentes em organismos inteligentes. Neste sentido, RNAs simplificam neurônios biológicos como sendo unidades de processamento, as quais têm a propensão natural para armazenar conhecimento experimental e torná-lo disponível para o uso. Mais detalhadamente, uma RNA produz saídas adequadas para entradas que não estavam presentes durante o seu treinamento, imitando, desta forma, a capacidade humana de aprender e generalizar fatos (padrões) [1], [2].

Esses sistemas mimetizam (grosseiramente) o cérebro humano de forma que o conhecimento de ambos são adquiridos a partir do ambiente em um processo de aprendizagem dado pela força de conexão (pesos sinápticos) entre os neurônios, no cérebro, e entre as redes, nos sistemas [3].

A partir da publicação do clássico livro editado por Rumelhart

A. Bonini Neto, Faculdade de Ciências e Engenharia - UNESP - Tupã Brasil (e-mail: bonini@tupa.unesp.br).

C. S. B. Bonini, Faculdade de Ciências Agronômicas e Tecnológicas UNESP - Dracena (e-mail: carolbonini@dracena.unesp.br).

B. S. Bisi, Faculdade de Ciências e Engenharia - UNESP - Tupã - Brasil (e-mail: beatriz_bisi@hotmail.com).

L. F. S. Coletta, Faculdade de Ciências e Engenharia - UNESP - Tupã Brasil (e-mail: luizfsc@tupa.unesp.br).

A. R. dos Reis, Faculdade de Ciências e Engenharia - UNESP - Tupã Brasil (e-mail: andrereis@tupa.unesp.br).

Corresponding author: A. Bonini Neto. e McClelland do PDP Research Group da Universidade da California em San Diego [4], a área de redes neurais teve um desenvolvimento explosivo com a multiplicação exponencial de periódicos, associações locais e internacionais, além do grande número de teses e artigos científicos produzidos e em produção [1], [5].

Com isso, vários trabalhos têm sido publicados ao redor do mundo. No Brasil, Soares e colaboradores [6], avaliaram o desempenho da RNA na predição da produtividade da cultura do feijão, na região fronteira oeste do estado do Rio Grande do Sul, com base em variáveis morfológicas da cultura. A rede implementada obteve um desempenho ótimo na previsão de produção. Em outro estudo, com o objetivo de classificar a fertilidade química do solo via RNA, os autores avaliaram os atributos químicos do solo, como $\mathrm{pH}$, capacidade de troca catiônica, saturação de base, fósforo, magnésio e potássio. A RNA foi uma ferramenta muito promissora na diferenciação do solo para fins de irrigação [7]. Dos resultados obtidos a situação ótima da rede obteve $78 \%$ dos resultados iguais aos desejados, com duas camadas de neurônios, uma das quais intermediária, com 5 neurônios, e uma camada de saída.

Já em [8] e [9] fizeram-se o uso de RNA para a classificação dos níveis de solos degradados de acordo com seus atributos químicos. Observou-se que os solos analisados apresentam fertilidade aparente muito baixa indicando sua degradação e também foi observado que quanto mais profundo o solo, menor é sua fertilidade aparente.

No exterior, em [10] utilizaram as RNAs para mapeamento de solo e caracterização das propriedades do solo relevantes para o planejamento ambiental; em [11], manipularam as RNAs do tipo multicamadas com o objetivo de prever solos de acordo com seus atributos.

Esses estudos devem-se ao grande poder de aplicação das RNAs nas mais diversas áreas do conhecimento humano. As RNAs são capazes de extrair informações não explícitas de exemplos de treinamento, de maneira que são adequadas para a tarefa de classificação e o reconhecimento de padrões, sendo especialmente úteis em cenários com imprecisão e ruído nos dados [12].

Este trabalho tem por objetivo analisar dados de solos em recuperação por meio de RNAs de forma que se possa classificá-los automaticamente em função de seus atributos físicos.

\section{MATERIAL E MÉTODOS}

\subsection{Area experimental}

O solo analisado no presente trabalho localiza-se no município 
de Selvíria, Mato Grosso do Sul (MS), Brasil. A região apresenta médias de precipitação anual de $1370 \mathrm{~mm}$, temperatura de $23,5^{\circ} \mathrm{C}$ e umidade relativa do ar entre 70 e $80 \%$. O solo original da área de estudo foi classificado Latossolo Vermelho distrófico [13]. Da área em estudo, foram retirados 8,6 $\mathrm{m}$ do perfil do solo original, para o uso na construção da Usina Hidrelétrica de Ilha Solteira, ficando exposto o subsolo da área em estudo, desde 1969 [14]. As amostras analisadas neste trabalho é do ano de 2012 e as camadas analisadas foram $0,0-0,1 \mathrm{~m}, 0,1-0,2 \mathrm{~m}$ e $0,2-0,4 \mathrm{~m}$. A Fig. 1 a seguir apresenta a área em estudo. Maiores detalhes da área experimental (histórico) podem ser encontrados em [15-17].

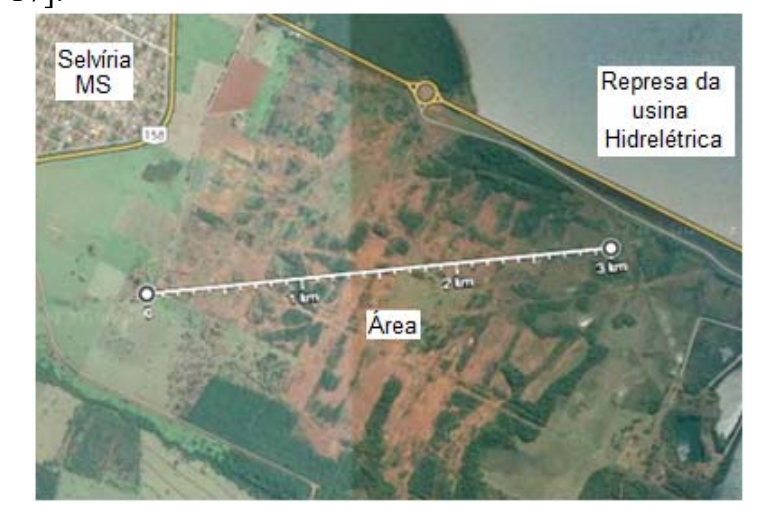

Fonte: Google maps

Figura 1. Área Experimental.

Para recuperação da qualidade física do solo foi realizado um experimento que consistiu em 9 tratamentos, sendo eles: calcário+guandu (c+g), calcário +gesso+guandu $(\mathrm{c}+\mathrm{ge}+\mathrm{g})$, calcário+gesso+mucuna-preta $(\mathrm{c}+\mathrm{ge}+\mathrm{mp})$, calcário+mucunapreta $(\mathrm{c}+\mathrm{mp})$, guandu $(\mathrm{g})$, vegetação nativa do cerrado - mata (ma), mucuna-preta (mp), solo exposto (se) e solo mobilizado (sm).

\subsection{Redes Neurais Artificiais (RNAs)}

A Fig. 2 ilustra um neurônio biológico (a) em contraste com um modelo de neurônio artificial (b).
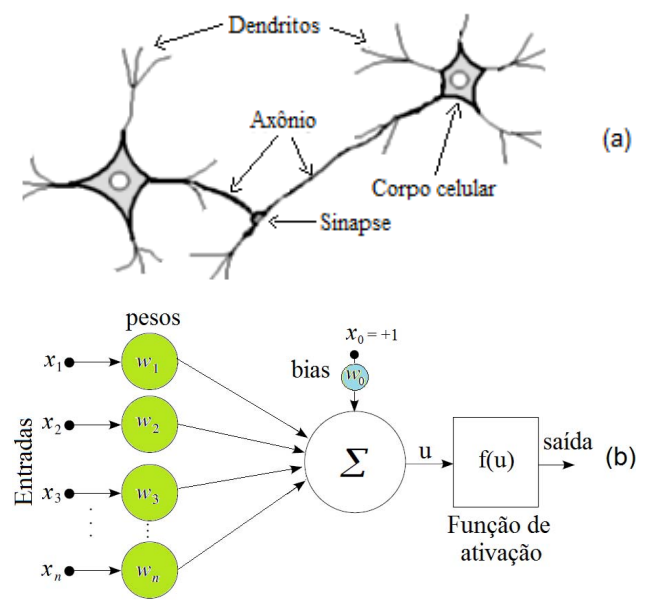

Figura 2. Rede neural: (a) Neurônio biológico, (b) Neurônio artificial.
Na Fig. 2 (b), $\sum$ representa o somatório dos produtos das entradas pelos respectivos pesos, ou seja, $u=\sum_{i=1}^{n} \mathbf{x}_{i} \mathbf{W}_{i}+$ bias (a soma do bias proporciona o aumento dos graus de liberdade, permitindo uma melhor adaptação, por parte da rede neural, ao conhecimento à ela fornecido). Por fim, $f(u)$ é a função de ativação para obter a saída da rede. A função de ativação utilizada neste trabalho para a saída de ambas as camadas é a função tangente sigmoide:

$$
f(u)=\left(1-e^{-\lambda u}\right) /\left(1+e^{-\lambda u}\right)
$$

em que $\lambda$ é uma constante arbitrária e corresponde a inclinação da curva.

Uma rede neural típica é composta de $n$ neurônios na camada de entrada, $m$ neurônios na camada intermediária e $i$ neurônios na camada de saída. Para este trabalho foram fixados $n=4$, duas configurações para $m, m=2 e m=10$ e por fim $i=1$, conforme ilustrado na Fig. 3 com $m=10$.

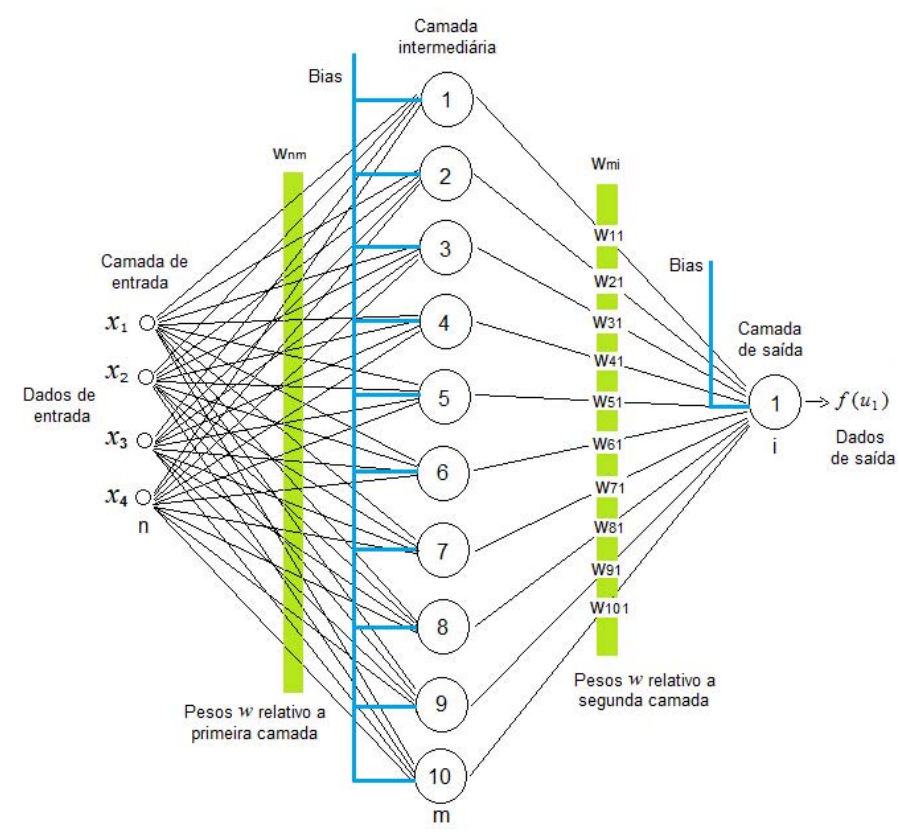

Figura 3. RNA utilizada neste trabalho.

A plataforma utilizada para a implementação computacional da RNA, bem como para a obtenção dos resultados, foi o Matlab [19]. Esta ferramenta permite o desenvolvimento de programas em uma linguagem de fácil assimilação, além de ser amplamente utilizada na engenharia.

\subsection{Treinamento da Rede Neural Artificial}

O treinamento de uma rede neural pode ser supervisionado ou não supervisionado. Enquanto $o$ treinamento não supervisionado não requer uma saída desejada (i.e., a rede realiza um treinamento auto-organizável levando em conta apenas os dados de entrada), o treinamento supervisionado 
considera a aprendizagem da rede a partir de dados de entrada e suas respectivas saídas desejadas [5]. Em outras palavras, o treinamento supervisionado, que é o adotado neste trabalho, consiste em conhecer um alvo a ser acertado para que a rede consiga adaptar seus pesos de modo que, posteriormente, no processo de operação, conhecido também como diagnóstico da rede, possa se classificar ou estimar dados que não fizeram parte no processo de treinamento. Portanto, pode-se dizer que, a aprendizagem de uma RNA se dá pelo ajuste de seus pesos, $\boldsymbol{W i}$, durante o treinamento e em função de dados de entrada cujas saídas são conhecidas.

A rede utilizada nesse trabalho é distribuída com $n$ entradas na primeira camada, $m$ neurônios na camada intermediária e $i$ neurônios na camada de saída. O método de treinamento supervisionado é o de retropropagação não recorrente (sem laços de realimentação) do inglês "feedforward backpropagation" [3], [4].

A tabela I apresenta as classes dos atributos físicos do solo (não recuperado, parcialmente recuperado e recuperado), com os valores restritos respectivamente para cada classe [18]. A tabela também apresenta as saídas desejadas com valores entre 0 e 1 , em que o 0 representa o solo não recuperado fisicamente e o valor 1 representa o solo recuperado. Outros valores poderiam ser especificados pelos autores, no entanto, uma única saída como proposto neste trabalho representa uma maior facilidade na interpretação dos resultados bem como a montagem dos gráficos comparando as saídas desejadas e as obtidas pela rede. Convém notar, portanto, que embora a RNA tenha sido usada para a classificação de três classes de solo (NR, PR e R), com discretização de sua saída produzida, os resultados apresentados a seguir consideram as saídas numéricas da rede (expressas em valores contínuos). Isto facilita a análise e compreensão do processo da rede, além de permitir a visualização geométrica dos resultados. Em outras palavras, a RNA usada é, em sua essência, uma rede de regressão.

TABELA I

CLASSES DOS ATRIBUTOS FÍSICOS DO SOLO

\begin{tabular}{|c|c|c|c|c|}
\hline \multicolumn{2}{|c|}{ Atributos } & $\begin{array}{c}\text { Não } \\
\text { recuperado } \\
(\mathrm{NR}) \\
\end{array}$ & $\begin{array}{l}\text { Parcialmente } \\
\text { recuperado } \\
(\mathrm{PR})\end{array}$ & $\begin{array}{l}\text { Recuperado } \\
\text { (R) }\end{array}$ \\
\hline \multicolumn{2}{|c|}{$\begin{array}{l}\text { Densidade do solo } \\
\qquad\left(\mathrm{g} / \mathrm{cm}^{3}\right)\end{array}$} & $(1,61-1,80)$ & $(1,56-1,60)$ & $(1,30-1,55)$ \\
\hline \multirow{2}{*}{$\begin{array}{l}\text { Porosidade } \\
\text { do solo }(\%)\end{array}$} & Macro. & $0-9$ & $10-13$ & $14-17$ \\
\hline & Micro. & $41-50$ & $37-40$ & $33-36$ \\
\hline \multicolumn{2}{|c|}{$\begin{array}{l}\text { Resistência do solo } \\
\qquad(\mathrm{MPa})\end{array}$} & $>2,8$ & $2,1-2.8$ & $0-2,0$ \\
\hline \multicolumn{2}{|c|}{ Saídas desejadas } & $0,0-0,33$ & $0,34-0,66$ & $0,67-1,0$ \\
\hline
\end{tabular}

III. RESULTADOS

\subsection{Desempenho da RNA}

Para o treinamento da rede foram utilizados dados de entrada representados por quatro atributos: densidade do solo, porosidade do solo (macroporosidade e microporosidade) e a resistência do solo à penetração. Como apresentado na tabela I, cada um desses atributos possuem restrições, as quais delimitam as saídas desejadas da rede de acordo com o dado de entrada. Assim, os solos podem, então, ser classificados como não recuperado, parcialmente recuperado e recuperado.

Utilizou-se um total de 63 amostras, sendo 21 de cada classe de recuperação (três classes). Do total, $60 \%$ foram utilizados para o treinamento (37 amostras), 20\% para validação (13 amostras) e $20 \%$ para teste (13 amostras). Inicialmente, foi criada uma rede com 10 neurônios na camada intermediária, no entanto, como no processo de treinamento foram utilizados apenas 63 amostras, optou-se em criar uma rede com um número bem reduzido de neurônios na camada intermediária, neste caso com 2 neurônios, $m=2$. A ideia foi mostrar que mesmo com um número reduzido de neurônios, a rede conseguiu obter resultados similares à uma rede mais robusta, ou seja, com $m=10$.

Após o treinamento da RNA, todas as saídas obtidas, de todas as amostras inseridas, foram submetidas ao processo de operação da rede, comparando-se, então, com as saídas desejadas. Este resultado são mostrados nas Fig. 4 (a) e 5.

$$
M S E=\frac{1}{n} \sum_{i=1}^{n}\left(Y_{\text {obtida }}-Y_{\text {desejada }}\right)^{2}
$$

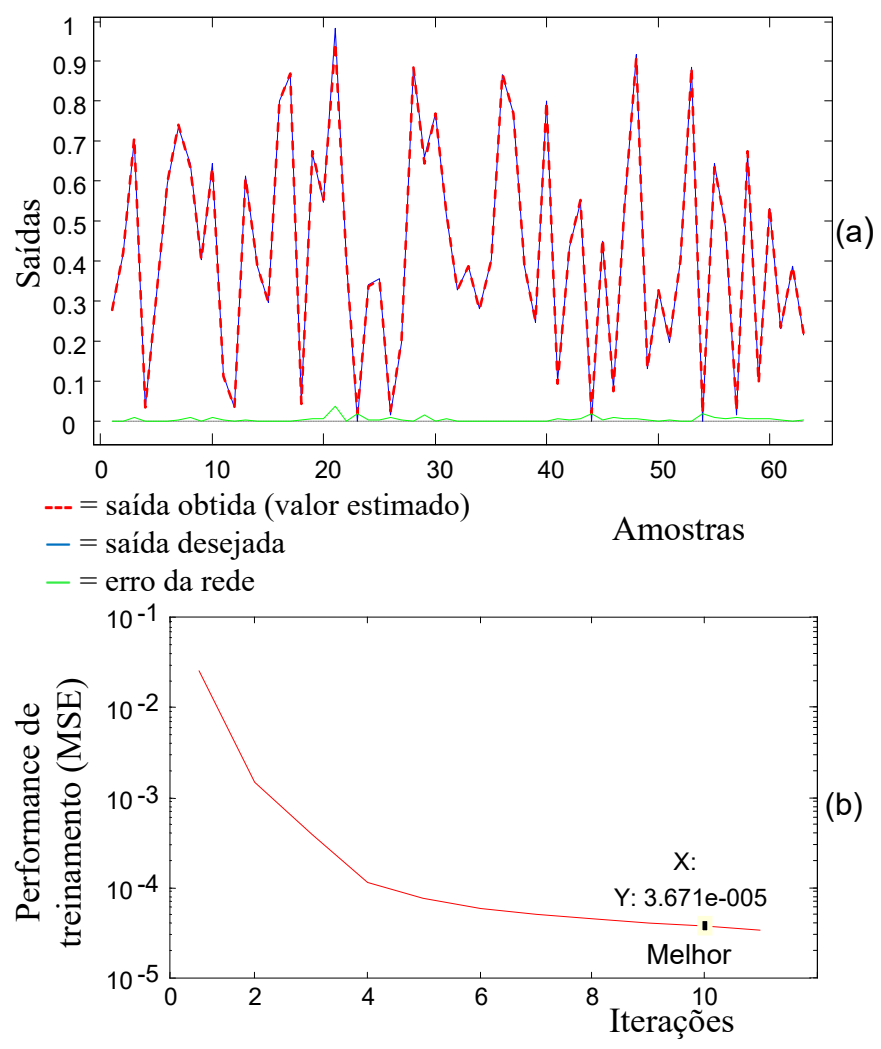



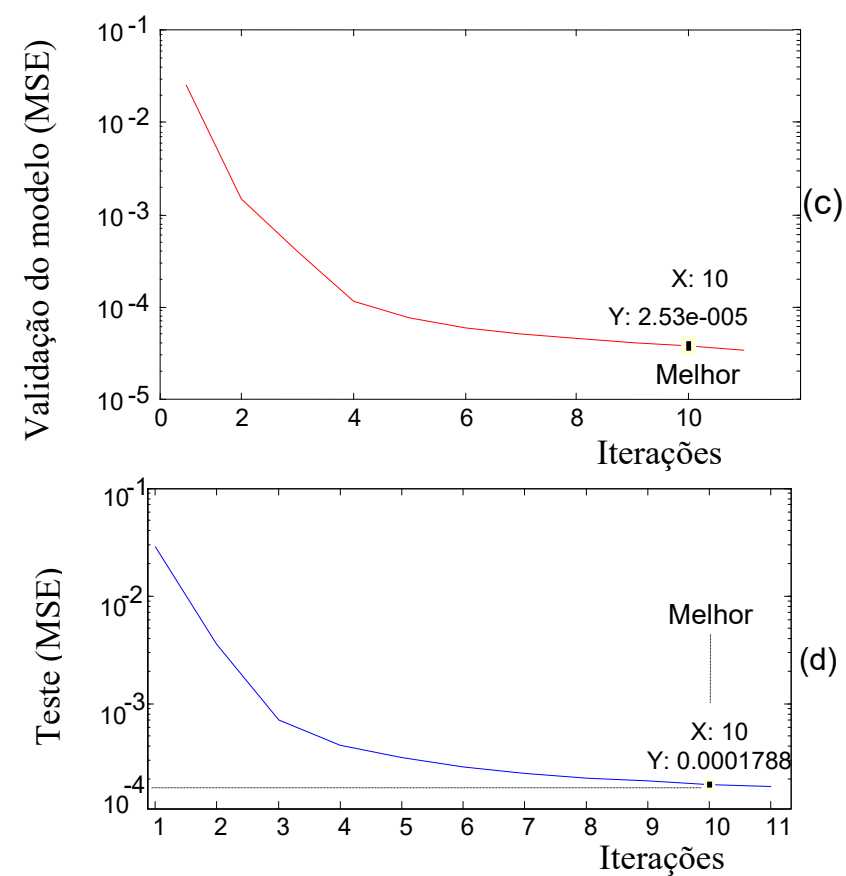

Figura 4. Processo de treinamento da rede para $100 \%$ das amostras dos atributos físicos do solo com $m=10$, (a) Saída obtida versus saída desejada, (b) Desempenho do treinamento da rede neural artificial (MSE), (c) Processo de validação da rede (MSE), (d) Processo de teste da rede (MSE).

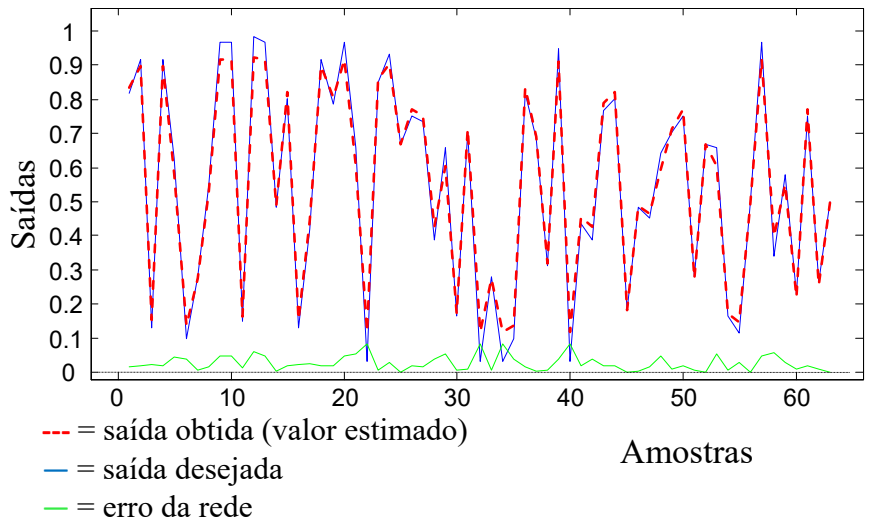

Figura 5. Processo de treinamento da rede para $100 \%$ das amostras dos atributos físicos do solo com $m=2$.

Observa-se que as curvas que representam as saídas obtidas pela RNA e as saídas desejadas são muito similares, indicando que a rede foi bem treinada, sendo capaz de classificar solos, não apenas amostras de treinamento, mas também qualquer tipo de amostra. Este resultado enfatiza o potencial de aplicação de RNAs, as quais podem atuar tanto como ferramentas de classificação, como também de previsão. As Fig. 4(b), (c) e (d) referem-se à performance do treinamento e da operação da rede, a validação do modelo e o teste. Para todos os testes o MSE (do inglês Mean Square Error) ficou em torno de $10^{-5}$ mostrando que os pesos $\boldsymbol{W i}$ foram todos ajustados para a rede desenvolvida. As tabelas II e III apresentam os parâmetros do treinamento da rede. O tempo do processador utilizado para o treinamento da rede com $m=10 \mathrm{e}$ $m=2$ foram de 4,342 e 2,026 segundos respectivamente, em um equipamento "Pentium Dual-Core E5800 3.20 GHz de 4,00 GB de memória", ou seja, o tempo de processamento das 10 e 7 iterações.
TABELA II

VALORES ESPECIFICADOS PARA O TREINAMENTO

\begin{tabular}{c|ccc}
\hline & $\begin{array}{c}\text { Valor } \\
\text { especificado } \\
\text { na rede }\end{array}$ & $\begin{array}{c}\text { Melhor valor } \\
\text { de } \\
\text { treinamento }\end{array}$ & $\begin{array}{c}\text { Número de } \\
\text { neurônios na } \\
\text { camada } \\
\text { intermediária }\end{array}$ \\
\hline $\begin{array}{c}\text { Iteraçõe } \\
\mathrm{s}\end{array}$ & 100 & 10 & $m=10$ \\
Tempo & inf & $4,342 \mathrm{seg}$ & \\
\hline $\begin{array}{c}\text { Iteraçõe } \\
\mathrm{s}\end{array}$ & 100 & 7 & $m=2$ \\
Tempo & inf & $2,026 \mathrm{seg}$ & \\
\hline
\end{tabular}

TABELA III

DESEMPENHO DA REDE NEURAL (MSE)

\begin{tabular}{l|cc}
\hline & $\begin{array}{c}\text { Melhor valor de } \\
\text { treinamento com 10 } \\
\text { iterações, } m=10\end{array}$ & $\begin{array}{c}\text { Melhor valor de } \\
\text { treinamento com 7 } \\
\text { iterações, } m=2\end{array}$ \\
\hline Treinamento & 0,00003671 & 0.0013151 \\
Validação & 0,0000253 & 0,0006946 \\
Teste & 0,0001788 & 0.0016239 \\
\hline
\end{tabular}

A Fig. 6 (a) e (b) a seguir descreve a relação entre as variáveis y (saída desejada) e x (saída obtida) com $m=10$ e $m=2$. Observa-se que o valor do $\mathrm{R}^{2}$ são de 0,9993 e 0,9907 respectivamente, mostrando que $99 \%$ da variável x (saída obtida) consegue ser explicada pelos métodos presentes no modelo, ou seja, mais explicativo é o modelo, melhor ele se ajusta à amostra [20]. Nesse contexto, pode-se dizer que para este trabalho, ao utilizar pequenas quantidades de amostras no treinamento, o número de neurônios na camada intermediária pode ser significativamente reduzido. No entanto, também há vários fatores que podem influenciar essas análises, como o número de entradas, tipo da rede, entre outros.
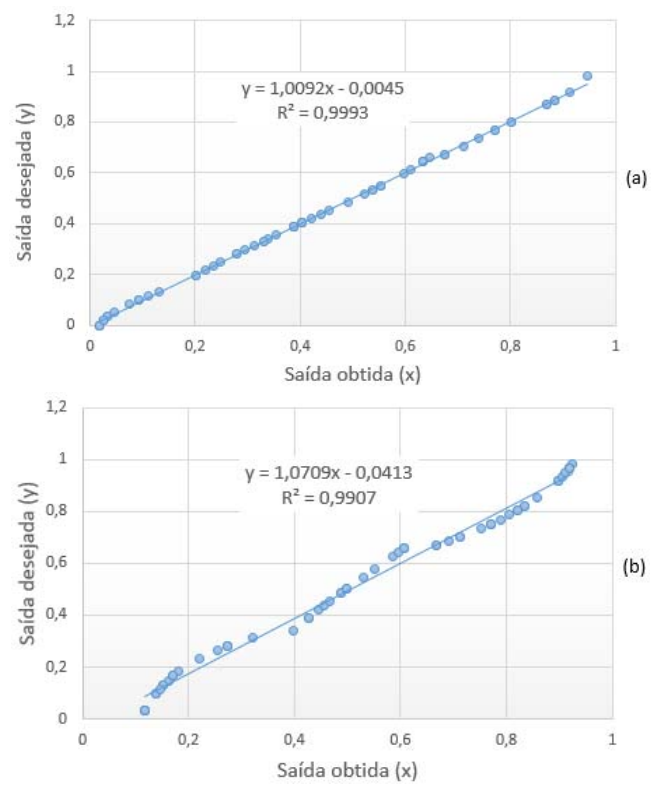

Figura 6. Análise de regressão entre as variáveis saída desejada e saída obtida, (a) $m=10$, (b) $m=2$. 


\subsection{Aplicação da RNA na análise de solo}

A Fig. 7 apresenta os resultados da fase de operação da rede para as 135 amostras de solos que não fizeram parte do treinamento, as quais foram obtidas do experimento realizado em Selvíria, Mato Grosso do Sul (MS). Na Fig. 7(a) foram utilizados 10 neurônios na camada intermediária, já na Fig. 7(b) apenas 2 neurônios. As amostras foram divididas em três profundidades com 45 amostras para cada, pode-se observar também as subdivisões dos tratamentos utilizados para a recuperação do solo, sendo 15 amostras para cada tratamento subdividido em 5 amostras por profundidade. Os tratamentos utilizados foram: calcário+guandu $(\mathrm{c}+\mathrm{g})$, calcário + gesso+guandu (c+ge+g), calcário+gesso+mucunapreta $(\mathrm{c}+\mathrm{ge}+\mathrm{mp})$, calcário + mucuna-preta $(\mathrm{c}+\mathrm{mp})$, guandu $(\mathrm{g})$, vegetação nativa do cerrado - mata (ma), mucuna-preta (mp), solo exposto (se) e solo mobilizado ( $\mathrm{sm}$ ). Da área em estudo, foram retirados $8,6 \mathrm{~m}$ do perfil do solo original, para o uso na construção da Usina Hidrelétrica de Ilha Solteira, ficando exposto o subsolo da área em estudo, desde 1969 [14], conforme ilustrado na Fig. 1.
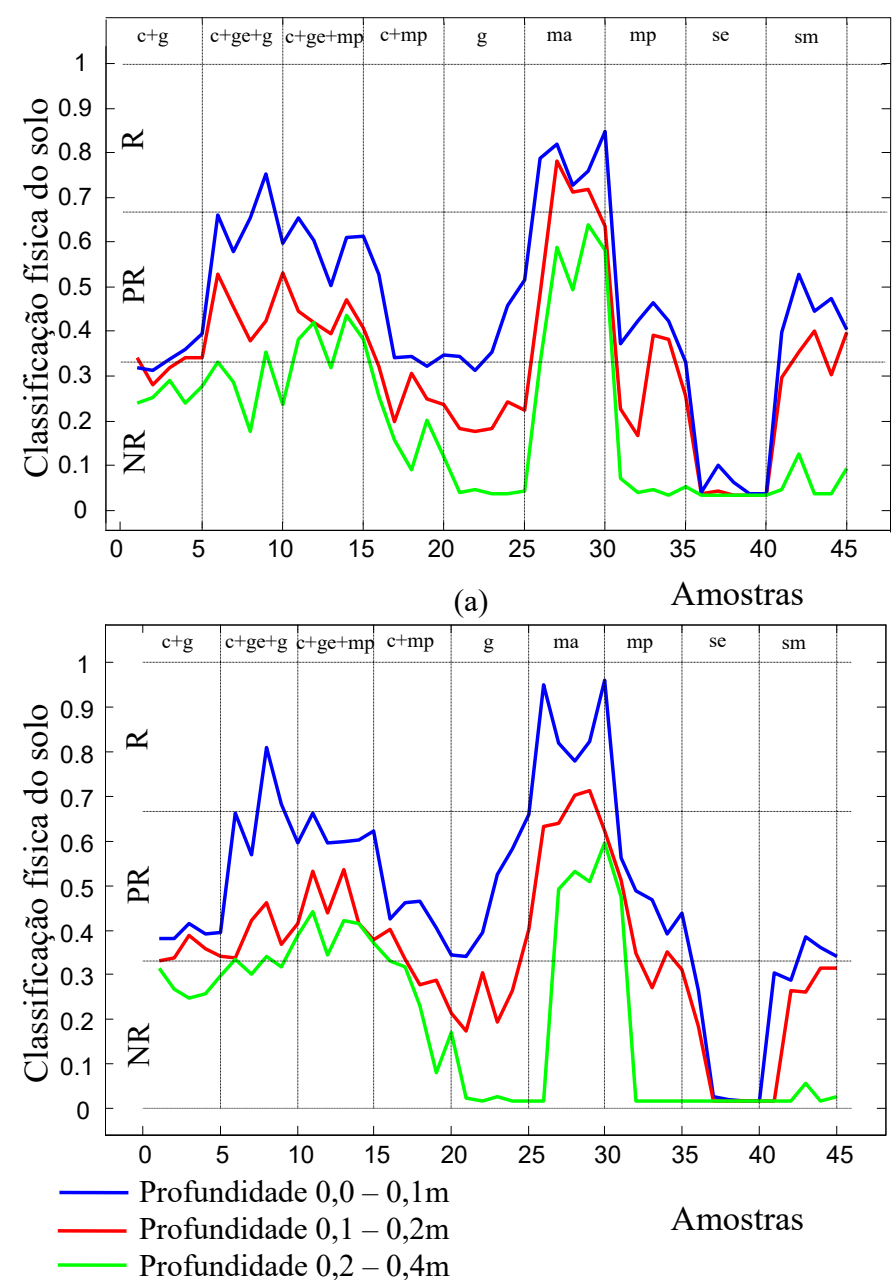

(b)

Figura 7. Resultados da classificação do solo pela RNA para cada tratamento e profundidade analisada, (a) $m=10$, (b) $m=2$.
Dos resultados aqui apresentados, focou-se apenas na rede com 10 neurônios na camada intermediária, uma vez que, para a rede com 2 neurônios, os resultados são similares conforme visto na Fig. 7.

Pode-se observar que a mata apresentou índice de solo recuperado, o que é de se esperar por ser uma vegetação nativa. Os demais tratamentos, em especial os que apresentam calcário, gesso e adubos verdes tiveram índice de solo em média parcialmente recuperado. Para os demais tratamentos, conforme os resultados na Fig. 7 apresentaram índices de solo não recuperado. Outro fator importante que pode ser observado são os resultados da classe de recuperação em função da profundidade analisada. A profundidade $0,0-0,1 \mathrm{~m}$ apresentou melhores resultados (solo recuperado) em relação a profundidade $0,1-0,2 \mathrm{~m}$ e assim por diante. Esse resultado é devido ao maior acúmulo de matéria orgânica nas camadas superficiais do solo provenientes das plantas instaladas nas parcelas experimentais.

As classificações como PR (parcialmente recuperado) e R (recuperado) foram maiores para os tratamentos calcário + gesso + guandu $(\mathrm{c}+\mathrm{ge}+\mathrm{g})$, calcário+gesso+mucunapreta $(\mathrm{c}+\mathrm{ge}+\mathrm{mp})$, respectivamente. Isso ocorre porque $\mathrm{o}$ calcário tem a capacidade de neutralizar a acidez do solo, e tornar o alumínio do solo não tóxico para o desenvolvimento do sistema radicular das plantas de guandu e mucuna preta. $\mathrm{O}$ gesso tem a capacidade de translocar o cálcio em maiores profundidades, o que permite o melhor desenvolvimento do sistema radicular das plantas. O maior volume do sistema radicular das plantas de guandu e mucuna preta permite maior absorção de água e nutrientes, o que reflete na maior produção de matéria fresca da parte aérea.

A Fig. 8 apresenta o gráfico de setores mostrando a porcentagem da recuperação do solo em função de cada profundidade estudada. Pode-se observar que na profundidade $0,0-0,1 \mathrm{~m}, 13 \%$ das amostras apresentaram solo recuperado, $65 \%$ solo parcialmente recuperado e $22 \%$ solo não recuperado, e conforme aumenta a profundidade, a porcentagem de solo não recuperado também aumenta.

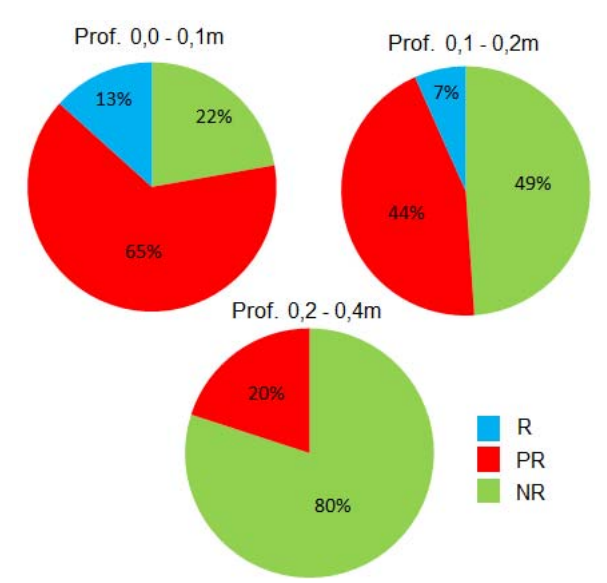

Figura 8. Resultados da classificação do solo pela RNA para as três profundidades analisadas. 
Na Fig. 9 é apresentado o gráfico de setores para cada tratamento utilizado, mostrando uma maior porcentagem de solo recuperado e parcialmente recuperado com a utilização de calcário, gesso e adubos verdes, desconsiderando a mata (ma), pois é uma vegetação nativa e com isso, mostrando um índice de solo recuperado, o que era de se esperar. Tomando como exemplo o tratamento $\mathrm{c}+\mathrm{ge}+\mathrm{g}$ (calcário+gesso+guandu) da

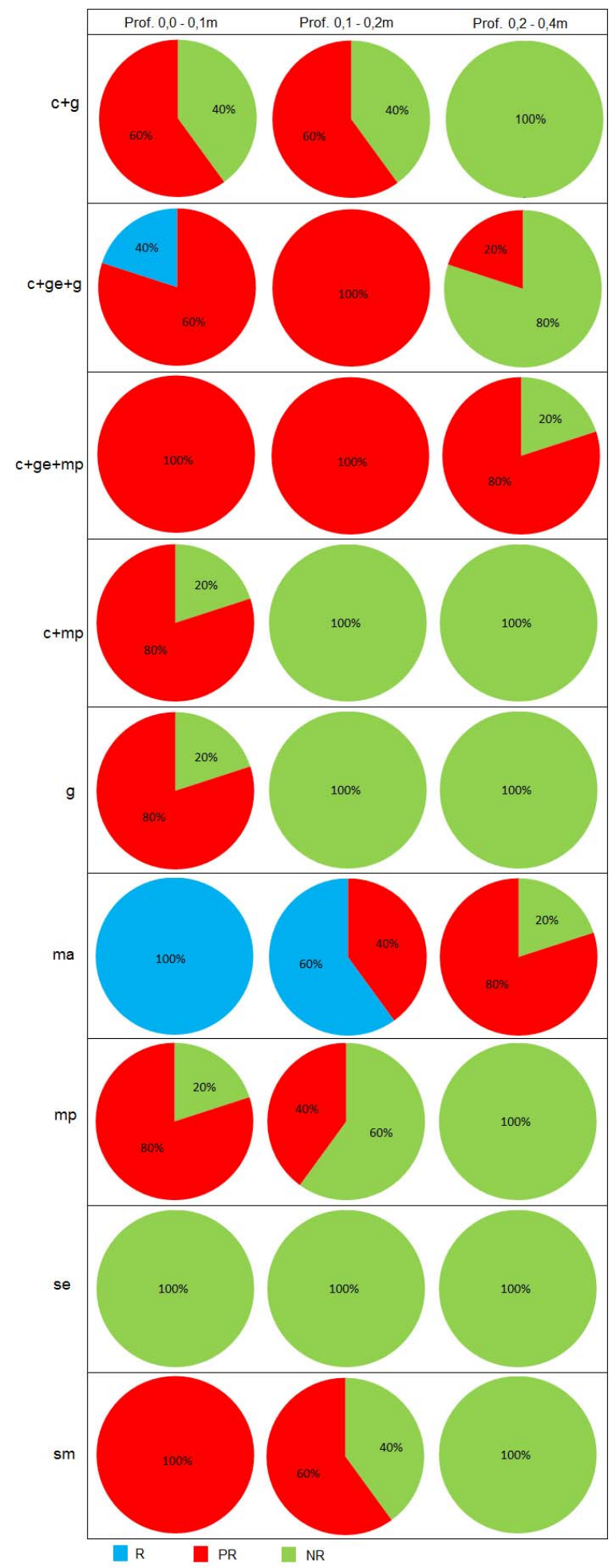

Figura 9. Resultados da classificação do solo pela RNA para cada tratamento.
Fig. 7, nota-se que na profundidade $0,0-0,1 \mathrm{~m}, 40 \%$ das amostras tiveram índices de solo recuperado (R) e $60 \%$ parcialmente recuperado (PR), na profundidade $0,1-0,2 \mathrm{~m}$ $100 \%$ das amostras tiveram classificação como PR e na profundidade $0,2-0,4 \mathrm{~m}, 20 \%$ das amostras com classificação PR e $80 \%$ com classificação NR (não recuperado). Já para o solo exposto (se), nota-se que para as três profundidades analisadas a RNA classificou o solo no índice de não recuperado (NR), isto se deve, ao fato de que o local não apresenta vegetação (solo inalterado após a retirada da vegetação para a construção da usina Hidrelétrica) contribuindo para o enfraquecimento do solo transformando-o em uma terra improdutiva (solo exposto). Os tratamentos calcário+guandu (c+g), calcário+mucuna-preta $(\mathrm{c}+\mathrm{mp})$, guandu (g), mucuna-preta (mp) apresentam resultados similares, principalmente para a profundidade $0,0-0,1 \mathrm{~m}$ com a maior parte das amostras classificados como solo parcialmente recuperado (PR). O mesmo ocorreu para o solo mobilizado (sm), por ser um solo mexido, ou melhor, revolvido por intermédio de equipamentos agrícolas como grade de discos, haste sulcadora entre outros, acarretando na redução da densidade do solo, da resistência mecânica e aumento da macroporosidade.

\section{CONCLUSÃO}

Neste trabalho foi desenvolvido um programa baseado em Redes Neurais Artificiais (RNAs) para a classificação de solos.

A rede foi desenvolvida, em particular, para classificar o Latossolo Vermelho de textura média, conforme as especificações fornecidas na tabela I.

A partir de seu treinamento, e com todos os pesos ajustados e validados, a RNA construída pôde atuar como um classificador de dados. Em especial, a rede foi capaz de fazer previsões/inferências a partir dos atributos do solo, permitindo a identificação de seus níveis de recuperação (solo não recuperado, solo parcialmente recuperado e solo recuperado).

Os resultados mostraram que o solo no qual foi feito o experimento ainda se encontra predominantemente não recuperado (NR), com média de $50,3 \%$ das amostras se comparado com $43 \%$ para solo parcialmente recuperado (PR) e $6,6 \%$ para solo recuperado $(\mathrm{R})$.

Desses índices, a rede mostrou que tratamentos com calcário, gesso e adubos verdes têm apresentado maiores porcentagens (maior potencial) de recuperação.

\section{AGRADECIMENTOS}

Os autores agradecem a UNESP e ao CNPq pelo apoio financeiro.

\section{REFERÊNCIAS}

[1] KOVACS, Z. L. Redes Neurais Artificiais: Fundamentos e Aplicações: Um texto básico. $4^{\mathrm{a}}$ ed. Editora Livraria da Física. 177 p. 2006. 
[2] ELIASMITH, C.; ANDERSON, C. H. Neural engineering: Computation, representation, and dynamics in neurobiological systems. MIT Press, Cambridge, MA. 2003.

[3] HAYKIN, S. Neural networks: a comprehensive foundation. 2. ed. Tsinghua University Press. 2001.

[4] RUMMELhaRT, D. E.; MCCLELLAND, J. L.; PDP Research Group. Parallel Distributed Processing - Explorations in the Microstructure of Cognition. v. 1: Foundations. A Bradford Book - The MIT Press. 1986.

[5] BRAGA, A. DE P.; CARVALHO, A. P. DE L. F. DE; LUDERMIR, T. B. Redes neurais artificiais: teoria e aplicações. 2. ed. Rio de Janeiro: LTC Editora, 2007.

[6] SOARES, F. C.; RUSSI, J. L.; ROBAINA, A. D. PEITER, M. X.; PARIZI, A. R. C. Uso de Rede Neural Artificial para predição da produção na cultura do feijoeiro. In: XLIII Congresso Brasileiro de Engenharia Agrícola-CONBEA. p. 1-7. 2014.

[7] BUCENE, L. C.; RODRIGUES, L. H. A. Utilização das Redes Neurais Artificiais para avaliação da produtividade do solo, visando classificação de terras para irrigação. Revista Brasileira de Engenharia Agrícola e Ambiental, Campina Grande, v. VIII, n. 2-3, p. 326-329. 2004.

[8] BISI, B. S.; BONINI NETO, A.; BONINI, C. S. B. Redes Neurais Artificiais: Utilização do Algoritmo Retropropagação para Classificação de Grupos em Biossistemas, Parte 1: Introdução Teórica. Fórum Ambiental da Alta Paulista, v. 11, p. 345-354. 2015.

[9] BISI, B. S.; BONINI NETO, A.; BONINI, C. S. B. Redes Neurais Artificiais: Utilização do Algoritmo Retropropagação para Classificação de Grupos em Biossistemas, Parte 2: Aplicação. Fórum Ambiental da Alta Paulista, v. 11, p. 194-207. 2015.

[10] BEUCHERA, A.; SIEMSSENA, R.; FRÖJDÖA, S.; ÖSTERHOLMA, P.; MARTINKAUPPIB, A. AND EDÉNB, P. Artificial neural network for mapping and characterization of acid sulfate soils: Application to Sirppujoki River catchment, southwestern Finland. Geoderma. v. 247248, p. 38-50. 2015.

[11] SILVEIRA, C. T.; OKA-FIORI, C.; SANTOS, L. J. C.; SIRTOLI, A. E.; SILVA, C. R.; BOTELHO, M. F. Soil prediction using artificial neural networks and topographic attributes. Geoderma, v. 195-196, p. 165-172. 2013.

[12] BISHOP, C. M. Pattern Recognition and Machine Learning, Information Science and Statistics. Springer-Verlag New York. 2006.

[13] EMBRAPA. Empresa Brasileira de Pesquisa Agropecuária. Ministério da Agricultura, Pecuária e Abastecimento. Sistema Brasileiro de Classificação de Solos. $3^{\mathrm{a}}$ ed. Rio de Janeiro: Embrapa CNPSO, 306p. 2013.

[14] ALVES, M. C.; SOUZA, Z. M. Recuperação do subsolo em área de empréstimo usada para construção de hidroelétrica. Revista Ciência Agronômica, 42: 301-309. 2011

[15] BONINI, C. S. B.; ALVES, M. C. Recovery of soil physical properties by green manure, liming, gypsum and pasture and spontaneous native species. Revista Brasileira de Ciência do Solo, 35: 1397-1406. 2011.

[16] BONINI, C. S. B.; ALVES, M C. Qualidade física de um Latossolo Vermelho em recuperação há dezessete anos. Revista Brasileira de Engenharia Agrícola e Ambiental (Online), v. 16, p. 329-336. 2012.

[17] BONINI, C. S. B.; ALVES, M. C. Estabilidade de agregados de um latossolo vermelho degradado em recuperação com adubos verdes, calcário e gesso. Revista Brasileira de Ciência do Solo, 35: 1263-1270. 2011.

[18] KIEHL, E.J. Manual de edafologia: Relações solo-planta. São Paulo: Ceres, 262p. 1979.

[19] MATHWORKS. MATLAB (MATrix LABoratory) Disponível em: $<$ http://www.mathworks.com>. Acesso em 21 de maio de 2016.

[20] PAgano, M.; GaUVReau, K. Princípios de Bioestatística. São Paulo: Cengage Learning, 506p. 2012.

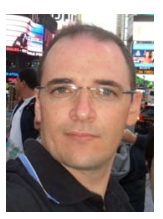

A. Bonini Neto, possui graduação em matemática pela Faculdade de Dracena - UNIFADRA, Brasil em 2002, mestrado e doutorado em Engenharia Elétrica pela Universidade Estadual Paulista - UNESP, campus de Ilha Solteira em 2006 e 2011 respectivamente. Fez pós-doutorado em Engenharia Elétrica com pesquisas em matemática aplicada, técnicas de parametrização em Sistemas Elétricos de
Potência. Atualmente é professor assistente na Faculdade de Ciências e Engenharia - FCE - UNESP - campus de Tupã, onde trabalha com pesquisas envolvendo técnicas matemáticas de parametrização e inteligência artificial (Lógica Fuzzy e Redes Neurais Artificiais).

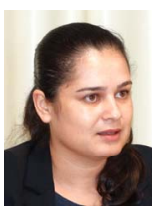

C. S. B. Bonini, possui graduação em Agronomia pela Universidade Estadual Paulista Júlio de Mesquita Filho, campus de Ilha Solteira (2007), mestrado em Agronomia pela Universidade Estadual Paulista Júlio de Mesquita Filho, campus de Ilha Solteira (2010) e doutorado sanduíche em Agronomia pela Universidade Estadual Paulista Júlio de Mesquita Filho e Universidade da Coruña (2012). Atualmente é professora assistente doutora da Faculdade de Ciências Agrárias e Tecnologicas - FCAT - UNESP, campus de Dracena, atuando principalmente nos seguintes temas, áreas degradadas, uso de resíduos na agricultura e sistemas integrados de produção.

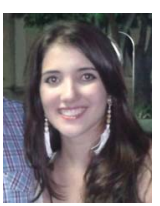

B. S. Bisi, graduanda no curso de Engenharia de Biossistemas da Faculdade de Ciências e Engenharia - FCE - UNESP campus de Tupã. Trabalha com pesquisas na área de matemática aplicada e inteligência artificial (Redes Neurais Artificiais) para a classificação de solos degradados.

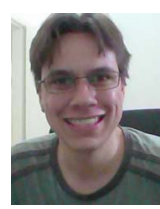

L. F. S. Coletta, graduado em Bacharelado em Informática pela Universidade de São Paulo (USP) em 2009. Concluiu o Mestrado em 2011 no Instituto de Ciências Matemáticas e de Computação da USP (ICMC-USP), onde também obteve seu título de Doutor, em 2015. Tem experiência na área de Ciência da Computação e, em especial, nas áreas de Mineração de Dados, Aprendizado de Máquina e Computação Bioinspirada. Atualmente é Professor Assistente Doutor na Faculdade de Ciências e Engenharia (FCE) da Universidade Estadual Paulista (UNESP - Campus de Tupã), onde conduz pesquisas envolvendo o grande campo da Inteligência Artificial.

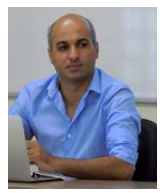

A. R. dos Reis, possui graduação em agronomia pela Universidade Estadual Paulista Júlio de Mesquita Filho (2005) e mestrado em Agronomia pela Universidade de São Paulo (2007). Recebeu o título de $\mathrm{PhD}$ pela Waseda University em 2013. Tem experiência na área de agronomia, com ênfase em fisiologia e bioquímica de plantas cultivadas, fertilidade e nutrição mineral de plantas. Atualmente é professor assistente na Faculdade de Ciências e Engenharia - FCE - UNESP - campus de Tupã e professor permanente no programa de pós-graduação em agronomia na Faculdade de Engenharia de Ilha Solteira (FEIS-UNESP). 